frequency of $\mathrm{CDe} / \mathrm{CDE}$ and $\mathrm{MN}$ people may be found, unless care is taken to study only those who have not been transfused. Previous transfusion may possibly be the explanation of the high $\mathrm{CDe} / \mathrm{cDE}$ frequency found in duodenal ulcer by Buckwalter and Tweed (1962).

We are grateful to the Research Committee of the United Liverpool Hospitals under the chairmanship of Lord Cohen of Birkenhead, to the Medical Research Council, and to the Nuffield Foundation for generous grants towards this work.

ADDENDUM.-Since writing this paper we have Rhgrouped (1) a series of 139 duodenal ulcer patients while they were in hospital, (2) a series of 111 duodenal ulcer patients who have not been in hospital for at least a year, and (3) a control series of 256 . We found the CDe/cDF frequencies to be $26.62 \%, 16.21 \%$, and $12.89 \%$ respectively. After the blood groupings had been carried out we studied the case sheets of the first series and found that approximately $50 \%$ of the patients had had a recent previous blood transfusion. Our figures, therefore, are in agreement with the theoretical frequencies given in this paper and are further evidence of previous recent blood transfusion being able to account for Buckwalter and Tweed's (1962) finding of a high $\mathrm{CDe} / \mathrm{cDE}$ frequency in duodenal ulcer.

REFERENCES

Buckwalter, J. A., and Tweed, G. V. (1962). J. Amer. med. Ass.

Mollison, P. L. (1962), Blood Transfusion in Clinical Medicine, 3rd ed. Blackwell, Oxford.

\title{
TUBELESS GASTRIC SURGERY
}

\author{
BY \\ W. GARDEN HENDRY, F.R.C.S., F.R.C.S.Ed. \\ Consultant Surgeon, Highlands General Hospital, London
}

It would seem to be current surgical practice on both sides of the Atlantic to use a naso-gastric tube for stomach decompression before and after routine gastric surgery, and in one clinic at least (Farris and Smith, 1956), in order to avoid a naso-gastric tube, it is the practice to use an indwelling gastrostomy tube for a few post-operative days.

In this short paper I propose to present evidence that this is entirely unnecessary, certainly for partial gastric resection and after vagus-nerve resection with a "drainage" procedure.

Below are presented two well-documented series which were begun in 1947, and the same routine preoperative care is being used to-day-a span of almost fifteen years. The first series comprises 114 cases of Billroth I partial gastrectomy for duodenal ulceration and lesser-curve ulceration; the second series is one of 118 cases of vagus-nerve resection and Finney pyloroplasty for duodenal ulcer and lesser-curve ulcer lesions. During this period, although these two procedures have been the methods of choice, a small number of Polya partial gastrectomies, with both post-colic and ante-colic anastomoses, and 20 cases of vagus resection and gastrojejunostomy, have been done without having to retreat from the tubeless regime.

\section{The Regime \\ Cases without Gastric Delay}

These are patients in whom the barium-meal investigation shows no residue or an insignificant residue after five hours. These cases come to operation after an overnight fast, without any special "gastric" preparation and no intubation.

Post-operative regime after any of the operative procedures mentioned in the preceding paragraph is as follows. (1) No Ryle's tube is passed, and no intravenous or other parenteral fluid therapy is used. (2) No antibiotic therapy is used except for special indications. (3) After full recovery from anaesthesia, the following strict progressive fluid regime is begun: 1 st 24 hours, 1 oz. ( $28 \mathrm{ml}$.) of water hourly by mouth ; 2nd 24 hours, $2 \mathrm{oz}$. (57 ml.) of water hourly by mouth; 3rd 24 hours, $3 \mathrm{oz}$. $(85 \mathrm{ml}$.) of water hourly by mouth ; 4th 24 hours, $4 \mathrm{oz}$. (114 ml.) of clear fluids hourly by mouth-these can include orange juice with glucose, tea, Bovril, etc. ; 5th 24 hours, a-very light diet with the addition of such items as bread-and-butter, junket, jelly, ice-cream, and scrambled egg.

A first-stage gastric dietary regime is now followed, going on to third-stage gastric diet at the end of a week, and after a further week a normal diet can be cautiously started if no chronic ulceration is to be healed. If chronic ulceration is present the gastric dietary regime would be continued for three to four weeks before resuming a normal dietary regime.

\section{Cases with Gastric Delay}

These are cases evidenced by significant barium residue after five hours. They certainly require preparation for operation, with a high-calorie fluid regime with added vitamins, and gastric lavage twice daily until the washings are clean and odourless, usually after two or three days. Cleansing of a severely obstructed stomach may, however, require as long as a week. In these cases the correction of dehydration may need adequate amounts of routine intravenous glucose and saline to achieve fluid balance.

Following this preparation, the "tubeless" regime detailed above is given without variation, and the experience is that recovery is uninterrupted.

The two series are analysed from this aspect as follows :

\begin{tabular}{c|c|c|c|c|c}
\hline Series & $\begin{array}{c}\text { No. of } \\
\text { Cases }\end{array}$ & $\begin{array}{c}\text { Type of } \\
\text { Operation }\end{array}$ & $\begin{array}{c}\text { Cases of } \\
\text { Overt Gastric } \\
\text { Retention } \\
\text { (Pre-op.) }\end{array}$ & $\begin{array}{c}\text { Cases of } \\
\text { Failure of } \\
\text { Tubeless } \\
\text { Regime }\end{array}$ & Mortality \\
\hline 1 & 114 & $\begin{array}{c}\text { Billroth I } \\
\text { partial } \\
\text { gastrectomy } \\
\text { Vagus resection } \\
\text { and Finney } \\
\text { pyloroplasty }\end{array}$ & $\begin{array}{c}19 \\
(16.6 \%)\end{array}$ & 0 & $\begin{array}{c}1 \text { case } \\
0.98 \%\end{array}$ \\
\hline
\end{tabular}

Two Comments.-(1) In the four cases of failure of the tubeless regime there was temporary gastric discomfort and moderate distension which necessitated the passing of a Ryle's tube. With added experience I believe it is possible that these cases could have been as easily handled by a slowing of the fluid increments by mouth, or a discontinuance of all fluid by mouth for a few hours. None of these cases developed any severe abdominal complication. (2) The one death from an 
abdominal complication occurred after severe gastroenteritis but without any leak of the pyloroplasty, or peritonitis. This was a case of gross pyloric stenosis which I think in retrospect did not have sufficient cleansing lavage pre-operatively.

\section{Advantages of Tubeless Regime}

It is self-evident that the discomfort to the patient is much minimized by the absence of a naso-gastric tube and of intravenous drip apparatus. The patients are easier to nurse, and are encouraged to be out of bed for short periods from the first post-operative day. Outof-bed activity is progressively lengthened each day, and so chest and thrombotic complications are minimized, and the psychological impression of rapid post-operative progress is a great encouragement to all patients. Sleep is much easier without tubes, because of the lack of a source of restriction to movement, and this also greatly aids rapid recovery.

\section{Summary}

A tubeless regime for gastric surgery is presented. Its application to two series of cases is detailed. Its advantages are briefly described.

REFERENCE

Farris, J. M., and Smith, G. K. (1956). Ann. Surg., 144, 475.

\section{Preliminary Communications}

\section{Seasonal Variation in the Clinical Onset of Leukaemia in Young People}

There are references in the older literature to variations in the incidence of leukaemia with season-for example, Forkner (1938)-but recently there has been little interest in this, and the term "season" does not appear in the latest British monograph (Hayhoe, 1960). As part of studies of leukaemia in young people (Lee, 1961) details of a sample of cases reported to the National Cancer Registration Scheme of England and Wales were available, and examination of these suggested that the clinical onset of the disease was not evenly spread through the year. A more detailed study was therefore made, and the first results are reported here.

The National Cancer Registration Scheme started in 1946 with a few hospitals, and it has been steadily expanded. The procedure is that an abstract card is completed for each patient by the participating hospital, or regional centre, and is sent to the General Register Office, which operates the scheme. The cases of leukaemia in patients under the age of 20 which were reported during the years 1946-59 have now been analysed, except for about $10 \%$ where the cards had been sent back to the hospital for follow-up.
On the abstract card is a box, "Month of first symptom." This is completed by the hospital, and the month given has been taken as the date of clinical onset for the purpose of the present analysis. The distribution of the 1,671 patients aged $0-19$ is shown in Fig. 1. There

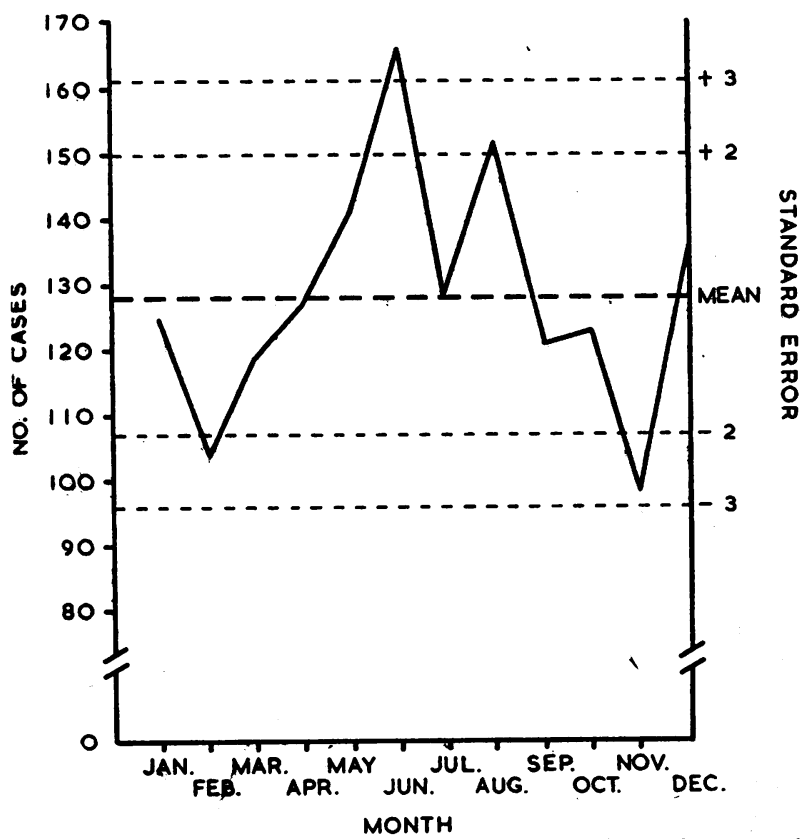

FIg. 1.-Month of elinical onset of levkaemia in patients aged 0 -19. $x^{2} 30.24$, D.F. 11, $P<0.005$. The chance that the difference between an observation and its expected value will exceed twice the standard error is about 1 in 20 . The chance that it will exceed three times the standard error is about 3 in 1,000. National Cancer Registration Scheme, England and Wales, 1946-59.

is an excess of cases with clinical onset in the summer, particularly in June. This distribution is unlikely to be due to chance. The excess of summer cases is smaller if the date of diagnosis is used rather than the date of clinical onset, and smaller again if the date of death is used. When the monthly numbers are corrected for variations in the length of the calendar months the excess in June over the monthly average is increased from 29 to $32 \%$, while the excess in August drops from 18 to $16 \%$.

The seasonal variation is found in both males and females. The summer peak was present in 1950-4 and 1955-9 (Table I), but was only doubtfully present in the small numbers of cases reported in 1946-9. Nearly all the cases in young people are acute, and removal of the $6.2 \%$ which were described as subacute or chronic does not alter the seasonal variations. The excess of cases beginning in the summer is found in each of the fiveyear age-groups from 0 to 19 (Table II). The summer peak is significant by the $\chi^{2}$ test for the cases aged 5-19, but not for the cases aged $0-4$, although, as would be

Table I.-Cases of Leukaemia in Patients Aged 0-19 by Month of Clinical Onset. National Cancer Registration Scheme, England and Wales

\begin{tabular}{|c|c|c|c|c|c|c|c|c|c|c|c|c|c|c|c|c|}
\hline & & & Jan. & Feb. & March & April & May & June & July & Aug. & Sept. & Oct. & Nov. & Dec. & $\begin{array}{l}\text { Not } \\
\text { Stated }\end{array}$ & Total \\
\hline $\begin{array}{r}\text { Acute*: } \\
1946-9 \\
1950-4 \\
1955-9\end{array}$ & $\ddot{a}$ & $\begin{array}{l}\ddot{ } \\
\cdots\end{array}$ & $\begin{array}{l}18 \\
46 \\
57\end{array}$ & $\begin{array}{l}14 \\
33 \\
53\end{array}$ & $\begin{array}{l}14 \\
46 \\
48\end{array}$ & $\begin{array}{l}14 \\
43 \\
61\end{array}$ & $\begin{array}{l}17 \\
51 \\
62\end{array}$ & $\begin{array}{l}13 \\
52 \\
89\end{array}$ & $\begin{array}{l}19 \\
35 \\
68\end{array}$ & $\begin{array}{l}13 \\
57 \\
74\end{array}$ & $\begin{array}{l}14 \\
29 \\
68\end{array}$ & $\begin{array}{l}14 \\
40 \\
62\end{array}$ & $\begin{array}{l}10 \\
34 \\
47\end{array}$ & $\begin{array}{l}14 \\
52 \\
58\end{array}$ & $\begin{array}{l}17 \\
29 \\
82\end{array}$ & $\begin{array}{l}191 \\
547 \\
829\end{array}$ \\
\hline $\begin{array}{c}\text { Subacute as } \\
1946-59\end{array}$ & $\begin{array}{l}\text { d ch } \\
. .\end{array}$ & aic: & 4 & 4 & 11 & 9 & 11 & 12 & 6 & 8 & 10 & 7 & 7 & 11 & 4 & 104 \\
\hline $\begin{array}{l}\text { Total: } \\
\text { 1946-59 }\end{array}$ & . & . & 125 & 104 & 119 & 127 & 141 & 166 & 128 & 152 & 121 & 123 & 98 & 135 & 132 & 1,671 \\
\hline
\end{tabular}

